\title{
ASEPTIC MENINGITIS IN ADULTS CAUSING BY VIRUS, BACTERIA, DRUG WITH SPECIAL REFERENCES TO ZOONOTIC PARASITES

$$
\text { By }
$$

\section{RAAFAT ZAHER ABDELRAHMAN ${ }^{1}$, AYMAN T. A. MORSY²,} AND TOSSON A. MORSY ${ }^{3}$

Consultant of Microbiology and Immunology, Military Medical Academy ${ }^{1}$, Consultant

of Tropical Medicine, The Ministry of Interior Hospitals ${ }^{2}$, and Department of

Parasitology, Faculty of Medicine, Ain Shams University, Cairo $11566^{3}$, Egypt

\begin{abstract}
Diagnosis of a patient with aseptic meningitis may be so-difficult because of the large variety of potential etiologic agents as viruses, fungi, parasites and some drugs and the overlap between self-limited viral illnesses and potentially fatal bacterial infections.
\end{abstract}

Key words: Aseptic Meningitis, Virus, Bacteria, Drug, Zoonotic Parasites

\section{Introduction}

The term aseptic meningitis refers to patients who have clinical and laboratory evidence for meningeal inflammation with negative routine bacterial cultures, commonest is enterovirus (Parasuraman et al, 2001). Additional etiologies include other infections, (mycobacteria, fungi, spirochet- es, and/or parasites), parameningeal infections, medications, and malignancy (Connolly and Hammer, 1990). Aseptic meningitis often has a similar presentation to bacterial meningitis (e.g., fever, headache, altered mental status, stiff neck, photophobia), which can be a life-threatening illness. But, in contrast to bacterial meningitis (Glimåker et al, 2016), the majority of patients with aseptic meningitis have a self-limited course that will resolve without specific therapy.

\section{Review, Discussion and Comments}

The assessment of patients with probable aseptic meningitis is complicated by the large number of potential etiologic agents and the relatively limited diagnostic tools for identifying specific pathogens. Patients with bacterial meningitis are usually quite ill and often present soon after symptom onset. The median duration of symptoms before admission was only 24 hours; ranged one hour to 14 days (de Gans and van de Beek, 2002). The classic triad of acute bacterial meningitis consists of fever, nuchal rigidity, and a change in mental status, although an appreciable number of patients do not have all three features (Durand et al, 1993). Most patients have high fevers, often greater than $38^{\circ} \mathrm{C}$ (Aronin et al, 1998), but a small percentage has hypothermia, but almost none has a normal temperature (Domingo et al, 1988). Headache is also common. The headache is typically described as severe and generalized. It is not easily confused with a normal headache. The following findings at presentation and during hospitalization were noted in a review of 279 episodes of community-acquired meningitis. The frequency of headache was not noted. Fever was present in 95 percent at presentation and developed in another four percent within the first 24 hours. Among survivors in whom such data were available, $19 \%$ had fever for ten or more consecutive days, but most had other possible causes of continued fever. Patients with no identifiable source of fever other than meningitis had an average of four consecutive days of fever (range 0 to 14 days). Nuchal rigidity was present in $88 \%$ on initial examination, and persisted for more than seven days in some patients despite overall improvement. Mental status was altered in $78 \%$. Most were confused or lethargic, but $22 \%$ were responsive only to pain and six $\%$ were unresponsive to all stimuli. The Herpes simplex virus type 1 (HSV-1) that caused encephalitis was commonest cause of sporadic fatal encephalitis worldwide. The clinical syndrome is often characterized by the rapid onset of fever, headache, seizures, fo- 
cal neurologic signs, and impaired consciousness. HSV-1 encephalitis is a devastating disease with significant morbidity and mortality, despite available antiviral therapy (Whitley and Kimberlin, 2005).

Meningitis versus Encephalitis: Presence or absence of normal brain function is the important distinguishing feature between encephalitis and meningitis. Patients with meningitis may be uncomfortable, lethargic, or distracted by headache, but their cerebral function remains normal. In encephalitis, however, abnormalities in brain function are common, including altered mental status, motor or sensory deficits, altered behavior and personality changes, and speech or movement disorders. Seizures and postictal states can be seen with meningitis alone and should not be construed as definitive evidence of encephalitis. Other neurologic manifestations include hemiparesis, flaccid paralysis, and paresthesias. However, the distinction between the two entities is frequently blurred since some patients may have both a parenchymal and meningeal process with clinical features of both. The patient is usually labeled as having meningitis or encephalitis based upon which features predominate in the illness although meningoencephalitis is also a common term that recognizes the overlap.

Generally, viral infections of the central nervous system (CNS) result in the clinical syndromes of aseptic meningitis or encephalitis (Connolly and Hammer, 1990). The true incidence of these infections is difficult to determine because the diagnosis may not be considered, many cases are unreported, or a specific viral etiology is never confirmed. However, these disorders occur with sufficient frequency that physicians should be familiar with the clinical manifestations, diagnostic techniques, and therapeutic options (Tyler, 2009).

Unfortunately, the clinical syndromes and results of routine laboratory tests are typically nonspecific. Thus, other infectious and noninfectious causes must be entertained when evaluating such patients, particularly those disorders that are treatable.

Viral meningitis: Some viruses produce aseptic meningitis as enteroviruses, herpes simplex virus (HSV), human immunodeficiency virus (HIV), West Nile virus (WNV), varicella-zoster virus (VZV), mum-ps, and lymphocytic choriomeningitis virus (LCM).

Enteroviruses: Aseptic meningitis occurring during the summer or fall is most likely to be caused by enteroviruses (e.g., Coxsackie, echovirus, other non-poliovirus enteroviruses), the most common cause of viral meningitis (Kupila et al, 2006). However, seasonal variation of certain CNS viral infections is relative and not absolute. Enteroviruses continue to cause 6 to 10 percent of cases of viral meningitis in the winter and spring despite their predilection for inciting illness in the late summer and fall. The presenting signs and symptoms of enteroviral meningitis are not distinctive. Symptoms onset were characteristically abrupt and typically includes headache, fever, nausea or vomiting, malaise, photophobia, and meningismus. Rash, diarrhea, and upper respiratory symptoms also occur (Meyer et al, 1960).

CSF findings are typical of other viral meningitides and include a white blood cell (WBC) count that is generally less than 250 cells/microL, a modest elevation in CSF protein concentration (generally less than 150 $\mathrm{mg} / \mathrm{dL}$ ), and a normal glucose concentration. Djukic et al. (2012) investigated the CSF changes during acute LNB. Routine CSF parameters [leukocyte count, protein, lactate and albumin concentrations, $\mathrm{CSF} /$ serum quotients of albumin (Q(Alb)), IgG, IgA \& IgM, and oligoclonal IgG bands] and Borrelia burgdorferi-specific antibody index were retrospectively studied in relation to the clinical presentation in patients diagnosed with acute LNB. A total of 118 patients with LNB were categorized into the following groups according to the symptoms at presentation; G1: polyradiculoneuritis (Bannwarth's syndrome), G2: isolated facial palsy and $\mathrm{G} 3$ : predominantly meningitic course of the 
disease. In addition to the CSF of patients with acute LNB, CSF of 19 patients with viral meningitis (VM) and 3 with neurolues (NL) were analyzed. There were 97 patients classified with definite LNB, and 21 as probable LNB. Neck stiffness and fever were reported by $15.3 \%$ of patients. Most of these patients were younger than 50 years. Polyradiculoneuritis was frequently found in patients older than 50 years. Lymphopleocytosis was found in all patients. Only 5 patients had a CSF lactate $\geq 3.5 \mathrm{mmol} / \mathrm{l}$, and mean CSF lactate level not elevated $(2.1 \pm 0.6 \mathrm{mmol} / \mathrm{l})$. The patients with definite LNB had significantly higher lactate levels than patients with probable LNB. Elevated lactate levels were accompanied by fever and headache. In the Reiber nomograms, intrathecal immunoglobulin synthesis was found for IgM in $70.2 \%$ followed by IgG in $19.5 \%$. Isoelectric focusing detected an intrathecal IgG synthesis in 83 patients. Elevated $\mathrm{BB}$ AIs in the CSF were found in 97 patients. Patients with VM showed lower $\mathrm{CSF}$ protein concentration and $\mathrm{CSF} / \mathrm{serum}$ quotients of albumin than LNB patients. In acute LNB, all patients had elevated CSF leukocyte counts. In contrast to infections by other bacteria, CSF lactate was lower than $3.5 \mathrm{mmol} / 1$ in all but 5 patients. CSF data did not differ between polyradiculoneuritis, facial palsy, and meningitis. CSF in LNB patients strongly differed from CSF in VM patients with respect to protein concentration and $\mathrm{CSF} /$ serum albumin quotient.

Up to two-thirds of patients with enteroviral meningitis have a polymorphonuclear predominance in the CSF when examined early in the course of the illness. Repeat lumbar puncture after 12 to 24 hours, if performed, generally shows an evolution to a lymphocytic predominance. PCR for enteroviruses can be considered if a definitive diagnosis is desired, or in the setting of an outbreak situation, but not necessary in all patients. CSF PCR for enteroviruses yields a diagnosis in up to $75 \%$ of patients with culture-negative aseptic meningitis. Among pa- tients with CNS manifestations and a negative CSF PCR, upper respiratory tract and gastrointestinal tract specimens for enterovirus PCR may be useful to establish a diagnosis of enterovirus infection (Perez-Velez et al, 2007).

HIV infection: Primary infection with HIV frequently presents as a mononucleosislike syndrome manifested by fever, malaise, lymphadenopathy, rash, and pharyngitis. A subset of them developed meningitis or meningoencephalitis manifested by headache, confusion, seizures or cranial nerve palsies.

Differential Diagnosis- The differential diagnosis of acute HIV infection includes mononucleosis due to Epstein-Barr virus (EBV) or cytomegalovirus, toxoplasmosis, rubella, syphilis, viral hepatitis, disseminated gonococcal infection, and other viral infections. A number of clinical findings help distinguish these disorders from primary HIV: Mucocutaneous ulceration is unusual in all of these entities and, if present, should heighten suspicion for acute HIV. Rash is uncommon in EBV mononucleosis (unless antibiotics were administered), CMV mononucleosis, and toxoplasmosis and tends to spare the palms and soles in rubella. The rash of primary HIV infection may resemble pityriasis rosea but marked constitutional symptoms are unusual in pityriasis. The abrupt onset of symptoms, pharyngeal edema with little associated tonsillar exudate or hypertrophy, and diarrhea all serve to distinguish acute HIV from EBV mononucleosis. A positive heterophile antibody test was reported uncommonly during acute HIV (Kelley et al, 2007); whether this represents a false positive test or reactivation of EBV during acute HIV is not clear. Regardless of the cause, the importance of this finding is that a positive heterophile antibody test does not exclude the diagnosis of acute HIV infection. Atypical lymphocytes also may be present in acute HIV although the incidence of atypical lymphocytosis is significantly less than in the classic mononucleosis syndromes $(<50 \%$ versus $90 \%)$ and the number 
of cells fewer (Pilcher et al, 2004). In most patients with HIV-1 meningitis, the clinical findings resolve without treatment, and patients may be erroneously assumed to have a benign cause of viral meningitis. Clinicians should have a high index of suspicion for primary HIV infection in patients at increased risk for acquisition of this virus and all patients should be questioned about possible risk factors. The identification of the patient with acute HIV infection is also important from a public health viewpoint since the risk of transmission is facilitated by high levels of viremia.

CSF profile characteristically has a lymphocytic pleocytosis, an elevated protein concentration, and normal glucose concentration. Documentation of primary HIV infection is accomplished by demonstration of seroconversion or detection of HIV-1 viremia in the absence of HIV antibody. Fitzgerald et al. (2016) stated that detection of acute HIV infection is vital in preventing onward transmission. HIV point-of-care testing (POCT) improved uptake of HIV testing but limited to third-generation assays, which only detect chronic HIV infection. They assessed the sensitivity of the new Alere HIV Combo POCT to detect acute HIV infection, and concluded that the Alere HIV Combo POCT test gave $88 \%$ sensitivity $95 \%$ CI (78\% to $98 \%$ ) and $100 \%$ specificity $95 \%$ CI $(99.7 \%$ to $100 \%)$ to detect p24 antigen.

Primary HSV is increasingly recognized as a cause of viral meningitis in adults. In contrast to HSV encephalitis, which is almost exclusively due to HSV-1, viral meningitis in immunocompetent adults is generally caused by HSV-2. Between $13 \& 36 \%$ of the patients presenting with primary genital herpes have clinical findings consistent with meningeal involvement, including headache, photophobia and meningismus. On the other hand, genital lesions are present in approximately $85 \%$ of patients with primary HSV-2 meningitis and generally precede the onset of CNS symptoms by seven days. CSF profile includes a pleocytosis with a predomi- nance of lymphocytes, and a normal CSF glucose concentration. HSV meningitis can also occur without evidence of genital lesions, although this was less common.

Papini (2012) in Italy reported that genital Herpes simplex virus infection was a recurrent, lifelong disease without cure. Strongest predictor for infection is a person's number of lifetime sex partners. HSV-2 was commonest responsible, although HSV-1 infections were rapidly increasing, particularly in adolescents, women and men who have sex with men. The natural history includes firstepisode of mucocutaneous infection, establishment of latency in the dorsal root ganglion, and subsequent reactivation. Most cases were transmitted via asymptomatic viral shedding. Atypical manifestations are common. Genital HSV-2 recurs six times more frequently than type 1 . Laboratory confirmation of the clinical diagnosis is recommended in all patients in order to guide a correct counseling and management. Real-time PCR and viral culture are gold standard for diagnosis. Serologic testing could be useful in patients with a questionable history. Counseling patients about the risk of transmission was crucial and helped prevent the spread of disease and neonatal complications.

Recurrent (Mollaret's) meningitis: Mollaret's meningitis is a form of recurrent benign lymphocytic meningitis (RBLM), not common illness characterized by more than three episodes of fever and meningismus lasting two to five days, followed by spontaneous resolution. There was a large patient-topatient variation in the time course to recurrence that could vary from weeks to years. One-half of patients can also exhibit transient neurological pictures, including seizures, hallucinations, diplopia, cranial nerve palsies, or altered consciousness (Shalabi and Whitley, 2006). The commonest etiologic agent in Mollaret's meningitis is HSV-2, but many patients do not have evidence of genital lesions at presentation time. Occasional cases are due to HSV-1 and some without established etiology. Finding of large granu- 
lar plasma cells on Papanicolaou's stain of CSF is pathognomonic of Mollaret's meningitis (Schlesinger et al, 1995). Diagnosis was by PCR for HSV DNA in CSF. Because of the infrequency of this clinical entity, no randomized treatment trials have been conducted; however, individual case reports suggesting benefit indicate that suppressive treatment with acyclovir or a related compound should be offered. Rawal et al. (2015) in India stated that Herpes simplex virus encephalitis (HSVE) is one of the most potentially fatal infectious diseases that must be detected very early. Combination of clinical history and examination, brain computed tomography or magnetic resonance imaging (MRI) and lumbar puncture have been used to establish a diagnosis. They presented a case of HSVE with normal CSF analysis, but typical MRI findings consistent with HSE and CSF PCR positive for Herpes simplex virus1 DNA, who responded to Acyclovir therapy with complete recovery. Noninfectious etiologies for Mollaret's meningitis were proposed. As an example, patients with an intracranial epidermoid-cyst or other cystic abnormalities in the brain can develop meningeal irritation due to intermittent leakage of irritating squamous material into the CSF. This may be detected acutely by polarizing microscopy of CSF. Imaging studies should be performed subsequently when the patient is asymptomatic, since the epidermoid cyst is often collapsed immediately after leaking its contents (Chan et al, 2003).

Lymphocytic choriomeningitis virus: Lymphocytic choriomeningitis virus (LCMV) is a human zoonosis caused by a rodentborne areana-virus. LCMV is excreted in the urine and feces of rodents, including mice, rats, and hamsters, and is transmitted to humans by exposure to secretions or excretions (by direct contact or aerosol) of infected animals or contaminated environmental surfaces. Infection is more common during winter months (Rousseau et al, 1997). Affected patients generally present with an influenza-like systemic illness accompanied by headache and meningismus. A minority of patients develop orchitis, parotitis, myopericarditis, or arthritis. CSF findings are typical of other causes of viral meningitis except that low glucose concentrations were observed in $20-30 \%$ of patients with LCMV meningitis and CSF WBC counts more than $1000 / \mathrm{microL}$ were usual. Diagnosis is by seroconversion to virus in paired sera. There was no specific antiviral therapy for LCMV. Schafer et al. (2015) reported that on April 26, 2013, United Network for Organ Sharing reported to CDC a cluster of ill organ transplant recipients in Iowa with a common organ donor. Infection with LCMV was suspected. LCMV is a rodent-borne virus commonly nonfatal, influenza-like illness and occasional aseptic meningitis, but when transmitted by organ transplantation or in utero is severe, life-threatening disease

Mumps: Aseptic meningitis is the most frequent extrasalivary complication of virus infection. Prior to the introduction of the mumps vaccine in 1967, this paramyxovirus was a relatively common cause of viral meningitis, accounting for between 10 and $20 \%$ of all cases. The commonest pictures were headache, low-grade fever, and mild nuchal rigidity. The onset of meningitis is variable and can occur before, during, or after an episode of mumps parotitis (Takeshima et al, 2015). Hikita et al. (2015) stated that pediatricians sometimes see patients with severe aseptic meningitis and prolonged fever or severe headache, or both. This condition has a good prognosis and is usually treated with supportive therapy. However, there was neither guideline nor consensus for the treatment of patients with severe aseptic meningitis. They investigated the relationship between disease severity and biomarkers. They found that the AMSS in MM was significantly higher than that in EM. IL-4, IL-6, IL-8, IL-10, and G-CSF levels in MM and EM CSF were higher than in control CSF. IFN- $\gamma$ levels were higher in MM than in controls $(\mathrm{p}<0.01)$. IL-10 and IFN- $\gamma$ levels in MM were higher than those in EM. They 
concluded MM was risky than EM. One likely reason is the higher CSF cytokine levels in MM. IFN- $\gamma$ may be a potentially strong biomarker of severity. Woo (2016) reported that because some parents were choosing to not vaccinate or only partially vaccinate their children, vaccine-preventable diseases that once were rarely seen in pediatric practice must now be considered part of the differential diagnosis when caring for the children. CSF profile typically reveals fewer than $500 \mathrm{WBC} / \mathrm{microL}$ with a lymphocytic predominance, but more than $1000 \mathrm{WBC} /$ microL and an early neutrophil predominance can sometimes see. CSF total protein is normal or slight elevated and CSF glucose levels may be mildly depressed.

Miscellaneous viruses: A number of other viruses can infrequently be associated with viral meningitis. In certain areas of the United States, arthropod-borne viruses can cause aseptic meningitis. West Nile virus (Gorman et al, 2016), St. Louis encephalitis virus (Reisen and Wheeler, 2016) and California encephalitis virus (Leber et al, 2016) all can cause aseptic meningitis but more frequently are associated with encephalitis. In California encephalitis virus Initial infection by the virus and primary spread of the virus causes the onset of non-specific symptoms such as headache and fever. Secondary spread and the multiplication of the virus in the CNS causes symptoms as stiff neck, lethargy and seizures. It then can result in encephalitis, when inflammation of the brain, produced by infection by the virus damages nerve cells, which affects signaling of the brain to the body. After the virus enters the body via a mosquito bite, the virus undergoes local replication at skin site where virus entered the body. A primary spread of virus occurs, with seeding of reticuloendothelial system, mainly in the liver, spleen, and lymph nodes. With the ongoing replication of the virus a secondary spread occurs, with the seeding of the CNS. Not all the cases reach this stage, depending on the efficiency of viral replication at the different stages and the degree of virus spread. The California encephalitis virus invades the CNS through either the cerebral capillary endothelial cells or the choroid plexus (Eldridge et al, 2009).

In Egypt, Corwin et al. (1992) estimated the prevalence of selected arboviral, rickettsial, and Hantaan viral antibody among a sample of schoolchildren from 4 villages in the Bilbeis area of the Nile river delta, Egypt. The prevalence of antibody was $9 \%$ $(21 / 223)$ for Sicilian sandfly fever, $4 \%$ $(8 / 223)$ for Rift Valley fever, 3\% (15/437) for West Nile virus and 9\% (28/315) for Hantaan (HTN) virus. Antibody was demonstrated among 22\% (93/418) of the same study subjects against Coxiella burnetti, 53\% (199/373) against Rickettsia typhi, and $37 \%$ (137/371) against $R$. conorii. El-Bahnasawy et al. (2013b) reported so many species of mosquito-borne diseases. The aseptic meningitis can also be associated with either primary varicella zoster infection or outbreaks of herpes zoster, Epstein-Barr virus, cytomegalovirus, human herpes virus-6, and adenoviruses. (Ihekwaba et al, 2008).

Spirochetes: Two major spirochetes are considered in differential diagnosis of aseptic meningitis; Treponema pallidum, causative agent of syphilis, and Borrelia burgdorferi agent of Lyme disease.

Syphilis: T. pallidum, the causative agent of syphilis, disseminates to the central nervous system during early infection. Syphilitic meningitis can present in the setting of secondary syphilis with headache, malaise, and disseminated rash. CSF data include a lymphocytic pleocytosis with an elevated protein concentration; occasionally a depressed glucose concentration may also be seen. Serum and CSF VDRL are nearly always positive. Leeyaphan et al. (2014) in Thailand reported that syphilis was increasing dramatically worldwide since 2000 , especially in men who have sex with men (MSM), and in those with human immunodeficiency virus infection. But, most previous reports studied about prevalence and risk-factors of syphilis in MSM population without statistical com- 
parison with non-MSM population. They concluded that Prevalence of syphilis was continuously increasing. MSM with syphilis significantly associated with younger age. Moreover, early stage of syphilis, VDRL titer higher than 1:32, and MSM-population were significantly related with the HIVinfection. Treatment regimen, MSM and HIV-co-infection did not significantly show influence on duration to cure. Drago et al. (2016) in Italy stated that although neurosyphilis (NS) keeps plaguing worldwide, often with oligosymptomatic and atypical manifestations, the most recent reports fail to provide useful information, like details of the clinical history and even of the previous early therapy. They conducted a survey of the literature of the last 5 years on the clinical presentation of NS, recording the aforementioned inaccuracies. One hundred and thirty-seven articles were collected, reporting on 286 patients. General paresis was the commonest form (49\%), often manifesting with cognitive impairment and psychiatric symptoms. Syphilitic meningitis was found in 63 patients $(22 \%)$, mainly with ocular or auditory involvement. Meningovascular and tabetic form were both found in $12 \%$ of cases. Gummatous and epileptic manifestations were rare. Literature perusal confirmed that NS prevalence was increasing with pictures atypical for timing and type of lesions.

Lyme disease: Lyme meningitis typically occurs in the late summer and early fall, the same time as the peak incidence of enteroviral meningitis. During the acute primary infection, some patients develop headache, neck stiffness, and photophobia. Fever is usually mild; Kernig and Brudzinski signs are usually absent on physical examination, and neurologic features can include cranial nerve palsies, especially involving the facial nerve, which may be bilateral. Ticks transmit more pathogens to humans and animals than any other arthropod. The $2.1 \mathrm{Gbp}$ nuclear genome of the tick, Ixodes scapularis (Say) the vectors pathogens that cause Lyme disease was described, human granulocytic anaplasmosis, babesiosis and other diseases (Gulia-Nuss et al, 2016).

Diagnosis of aseptic meningitis due to Lyme disease is facilitated when other characteristic findings are present, such as erythema chronicum migrans. When Lyme meningitis occurs alone, the diagnosis can be missed unless the clinician considers other risk factors, such as potential exposure to tick bites or travel history. Elhelw et al. (2014) investigated B. burgdorferi infection as an emerging zoonosis neglected in Egypt. A total number of 92 animals, tick and human companion specimens were collected and subjected for culture, PCR and/or serodetection. B. burgdorferi was detected and isolated from Egyptian animal breeds. They also detected the presence of outer surface protein A gene of $B$. burgdorferi by PCR as well as anti- $B$. burgdorferi-IgM by ELISA in human contacts who were suffering from fever of unknown origin. This report represents the first systematic study on animals associated with patients suffering from febrile illness to confirm the emerging of such neglected zoonosis in Egypt. Besides, ElBahnasawy et al. (2012) reported that many Egyptian animals (farm, domestic, pets) and carnivores were infested with many species soft and hard ticks.

Tick-borne diseases: Tick-borne diseases that can be considered in the differential diagnosis of aseptic meningitis include Rocky Mountain spotted fever and ehrlichiosis.

Rocky Mountain spotted fever: In the early phase of illness, patients with RMSF can present with fever, a severe headache, malaise, myalgias, arthralgias, and nausea with or without vomiting. If a lumbar puncture is performed to evaluate the headache, CSF findings can include a mild lymphocytic pleocytosis that can be confused with viral meningitis. Less than one-half of patients develop a rash in the first 72 hours of illness. Biggs et al. (2016) reported the 2006 CDC recommendations on the diagnosis and management of tick-borne rickettsial diseases in the USA and includes information on the 
practical aspects of epidemiology, clinical assessment, treatment, laboratory diagnosis, and prevention of tick-borne rickettsial diseases. CDC Rickettsial Zoonoses Branch, in consultation with external clinical and academic specialists and public health professionals, developed this report to assist health care providers and public health professionals to 1) recognize key epidemiologic features and clinical pictures of tick-borne rickettsial diseases, 2) recognize that doxycycline is treatment of choice for suspected tick-borne rickettsial diseases in adults and children, 3) understand early empiric antibacterial therapy can prevent severe disease and death, 4) request appropriate confirmatory diagnostic tests and Know their usefulness and limitations, and 5) report probable and confirmed cases of tick-borne rickettsial diseases to public health authorities

Ehrlichiosis: Patients with ehrlichiosis present in a similar manner as those with RMSF as with fever and nonspecific symptoms such as malaise, myalgia, headache\& chills. Rash, which can be macular, maculopapular, or petechial, occurs in a few patients.

Neurologic symptoms, including mental status changes, stiff neck, and clonus occur in some cases. CSF findings include a lymphocytic pleocytosis with elevated protein. In one case report, characteristic inclusions within mononuclear cells were seen, compatible with Ehrlichia morulae. Toom et al. (2016) in the Netherlands reported that in dogs with canine monocytic ehrlichiosis (CME), respiratory signs are uncommon and clinical and radiographic signs of interstitial pneumonia are poorly described. But, in man monocytic ehrlichiosis, respiratory signs are common and signs of interstitial pneumonia are well known. Pulmonary hypertension $(\mathrm{PH})$ is classified based on the underlying disease and its treatment is aimed at reducing the clinical signs and, if possible, addressing the primary disease process. $\mathrm{PH}$ is often irreversible, but can be reversible if it is secondary to a treatable underlying etiology. CME is currently not generally rec- ognized as one of the possible diseases leading to interstitial pneumonia and secondary $\mathrm{PH}$ in dogs. Only one case of $\mathrm{PH}$ associated with CME has been reported worldwide. They presented a seven-year-old; male intact, mixed breed dog was presented with 2 weeks history of lethargy and dyspnea. The dog previously lived in the Cape Verdean islands. Physical examination showed signs of right-sided congestive heart failure and poor peripheral perfusion. Thoracic radiography showed moderate right-sided cardiomegaly with dilation of the main pulmonary artery and a mild diffuse interstitial lung pattern with peribronchial cuffing. Echocardiography showed severe pulmonary hypertension with an estimated pressure gradient of $136 \mathrm{~mm} \mathrm{Hg}$. On arterial blood gas analysis, severe hypoxemia was found and complete blood count revealed moderate regenerative anemia and severe thrombocytopenia. A severe gamma hyperglobulinemia was also documented. The serology for Ehrlichia canis was highly positive. Treatment with oxygen supplementation, a typed packed red blood cell transfusion and medical therapy with doxycycline, pimobendan and sildenafil was initiated and the dog improved clinically. Approximately 2 weeks later, there was complete resolution of all clinical signs and marked improvement of the PH. Krbková et al. (2016) in Czech Republic examined evidence of positive antibodies against immunogenic proteins of $\mathrm{An}$ aplasma phagocytophilum in patients with other tick-borne infections and to diagnose possible co-infections, 412 serum specimens were tested by immunoblotting using three specific Anaplasma antigens: surface proteins p44 and Asp62 and outer membrane protein A (OmpA). In total, 284 serum samples from children with Lyme borreliosis and 12 serum samples from children with tick-borne encephalitis were tested. Patients' sera with viral aseptic meningitis $(n=47)$ and from blood donors $(n=69)$ were used as controls. All serum specimens from patients with tick-borne infections submitted for this 
study, six samples $(2 \cdot 0 \%)$ showed positive IgM reactions and seven samples $(2 \cdot 4 \%)$ were IgG positive for A. phagocytophilum by immunoblot. Borderline reactivity was found in 30 samples $(10 \cdot 14 \%)$ for $\operatorname{IgM}$ and 36 samples $(12 \cdot 2 \%)$ for IgG. The difference between patients and blood donors was statistically significant for $\operatorname{IgM}(\mathrm{P}=0.006)$ and for $\operatorname{IgG}(\mathrm{P}=0.0007)$ antibodies. A statistically significant result was obtained for $\operatorname{IgG}(\mathrm{P}$ $=0.02$ ) but not for IgM between patients and children with aseptic meningitis. Immunoblot using three specific antigens provides novel information about the positivity of antibodies to $A$. phagocytophilum in children with other tick-borne infections. Taking into account clinical and laboratory findings of children despite antibody positivity, no case of human granulocytic anaplasmosis was demonstrated.

Fungi: Two major fungal infections must be considered in differential diagnosis of aseptic meningitis include cryptococcus and coccidioidomycosis. C. neoformans produces infection following inhalation through the respiratory tract. The organism disseminates hematogenously and has a propensity to localize to CNS, particularly in patients with advanced AIDS. Symptoms typically begin in an indolent fashion, usually over a period of one to two weeks. The three commonest symptoms are fever, malaise, and headache; stiff neck, photophobia, and vomiting in one-fourth to one-third of patients. The CSF WBC count is typically low $(<50 / \mathrm{microL})$ with a mononuclear predominance and the protein and glucose concentrations are usually only slightly abnormal. Sun and Shi (2016) in USA noticed swarming behavior of neutrophils in both sterile injury and infection models and the unveiled mechanisms. They used live-cell imaging and observed in vitro neutrophil swarming toward $C$. neoformans, a fungal pathogen causing human meningoencephalitis. Complement C3 \& CD11b expression were essential for neutronphils to form cell swarms surrounding C. neoformans. Leukotriene B4 (LTB4) was quickly released by neutrophils during their interactions with $C$. neoformans. Blockade of LTB4 synthesis inhibited swarming responded. Importantly, blockade of LTB4 synthesis also significantly reduced neutrophil recruitment in the lung vasculature of mice infected intravenously with $C$. neoformans, demonstrating a critical role of LTB4 in intravascular neutrophil swarming during infection. First report of neutrophil dynamics of swarming towards a microorganism in vitro was mediated by complement \&LTB4.

Coccidioides immitis is endemic in desert regions of the southwestern United States and Central and South America. This infection has protean manifestations, and primary infection is frequently unrecognized. Meningitis is the most lethal complication of coccidioidomycosis and is therefore crucial to recognize. Symptoms of meningitis, including persistent and severe headache, usually develop within several months of the initial infection. Abnormal neurologic findings on physical examination are frequently absent early in the course of coccidioidal meningitis. CSF WBC counts ranges from one to several hundred cells. A significant numbers of eosinophils may be present, but not specific for coccidioidal meningitis. CSF glucose concentration may be depressed and is occasionally profoundly low in association with an elevation of CSF protein concentration. Kusne et al. (2916) in USA reported that donor-derived coccidioidomycosis caused unexpected morbidity and mortality in transplant recipients. They added that all proven or probable reports to the Disease Transmission Advisory Committee between 2005 and August, 2012 were reviewed. Six reports were discovered. In 4 of 6 , the infection was first detected at autopsy in the recipient. In 2 cases it was in the donor. Twenty-one recipients received organs from these 6 donors. Transmission occurred in $43 \%$ at a median of 30 days post-transplant with a mortality rate of $28.5 \%$. Eleven recipients received pre-emptive antifungals, $7 \mathrm{did}$ not receive treatment, and treatment information 
was not reported for 3 recipients. Five of 7 who did not receive prophylaxis/treatment expired and all received early therapy survived. Six deaths occurred 14 to 55 days after transplant; median of 21 days. For exposed recipients, donor-derived coccidioidomycosis is a significant cause of morbidity and mortality. Evidence of infection in one recipient should prompt immediate evaluation for treatment of all other recipients from the same donor as preemptive treatment was effective.

Tuberculous meningitis: Patients with tuberculous meningitis frequently have protracted headache, vomiting, confusion, and varying degrees of cranial nerve signs. Mental status changes can occur, leading to coma, seizures, and at times hemiparesis. Signs of disseminated TB are of diagnostic importance, but are often absent. CSF analysis typically shows elevated protein and lowered glucose concentrations with a mononuclear pleocytosis. Xu et al. (2016) in China reported that a one-year old boy admitted to hospital for lethargy with vomiting over 3 days. Neurological examination showed abnormalities. CSF examination showed evidence of meningitis. A purified protein derivative (PPD) test, T-SPOT.TB and radiological examination indicated tuberculous meningitis. During treatment, child developed hypertension, sinus tachycardia, tachypnoea, dystonia and high fever. Episodes improved after the administration of propranolol, artane and clonazepam. Paroxysmal sympathetic hyperactivity is a rare manifestation of tuberculous meningitis. They stated that early detection was very important to avoid diagnostic errors and overtreatment.

Bacteria: There are a variety of ways in which bacterial infections led to a clinical picture of aseptic meningitis with a CSF pleocytosis: Parameningeal sources, such as an epidural or subdural abscess, sinus, or ear infection, can occasionally extend to involve the central nervous system. A thorough history and physical examination led to appropriate imaging and the correct diagnosis.
Humaid et al. (2014) in Saudi Arabia determined the prevalence of otitis media with effusion (OME) among school children in Qassim region and its risk factors in affected children. They concluded that prevalence of OME in Qassim Region reached 7.5\% in school children; aged less than 8 years, family size more than 4 members in household, mother education less than secondary school education, living in rural area and recurrent AOM are found to be predictors of OME in Qassim Region. In this children population of otoscopy and tympanometry should be used as screening tools for OME.

Ragab et al. (2015) reported that acute rhinosinusitis (ARS) is a common pediatric problem and determined the efficacy of normal nasal saline irrigation (NSI) with or without amoxicillin in treatment of acute rhinosinusitis (ARS) in children. They studied 62 patients with ARS. In amoxicillin group (31 patients); clinical cure $26(83.9 \%)$ in comparison to $22(71 \%)$ patients in NSI without antibiotics group (31 patients). No differences between groups in the reported nasal symptom scores and total symptoms scores improvements at day $7(\mathrm{p}=0.09$ and $0.65)$ and day $14(\mathrm{p}=0.29$ and 0.14$)$, respectively. The mean total PRQLQ values had no differences between both groups after the 2 weeks of treatment $(p=0.06)$. At day 7 , MM neutrophils reduced significantly in amoxicillin group in comparison to placebo group $(p=0.004)$. At day 14 , the MM cytological content had no differences between both groups $(p=0.07)$. Normal NSI with placebo has less reported adverse effects than amoxicillin and nasal saline irrigations $(p=0.005)$. They concluded that NSI used alone with the same clinical, bacteriological and cytological cellular changes efficacy and with higher safety profile than amoxicillin after 14 days of treatment in uncomplicated clinically diagnosed ARS in children.

El-Kholy et al. (2015) in Egypt evaluated the serological and molecular methods for the diagnosis of infective endocarditis. One hundred and thirty-two cases were diag- 
nosed as definite IE. Causative organisms were detected by blood cultures in 40 of cases. Blood culture-negative endocarditis (BCNE) represented $69.7 \%$. Of these cases, PCR followed by sequencing on blood and valvular tissue could diagnose five cases of Aspergillus flavus. Eleven patients with BCNE $(8.3 \%)$ diagnosed as zoonotic endocarditis by serology and PCR including five cases of Brucella spp, four cases of Bartonella spp and two cases of Coxiella burnetii. PCR detected three cases of Brucella spp and two cases of Bartonella spp, while cases of $C$. burnetii were PCR negative. 11 diagnostic tools decreased the percentage of non-identified cases of BCNE from 69.7 to $49.2 \%$. They concluded that serologic and molecular tools diagnosed of blood culturenegative endocarditis. Bodman et al. (2016) stated that spinal epidural abscesses were an uncommon cause of spinal cord injury but, due to size and pre-sence of neurological deficits, urgent neurosurgical intervention may be required. They presented a unique case of a patient presenting with a spinal epidural collection several days after a fall. While a spinal epidural hematoma was suspected based on the patient's history and MRI findings, a spinal epidural abscess was found during surgery. The patient underwent laminectomy and instrumented fusion with successful treatment of her infection. Schneider and Pomidor (2016) in USA reported that Neurologic complications in $20 \%-40 \%$ of patients with infective endocarditis. Mycotic aneurysms are one example of these complications, and although rare, they could confound a patient's recovery and increase morbidity and mortality. They examined one patient's experience and the devastating effects that this complication had on his life. They concluded that information helped to support neurological nurses in refining care and facilitating best possible recovery for patients who developed this condition.

Parasites: selected some interesting cases.

Helminthes: Mazyad et al. (1999) in Egypt stated that affection of the spinal cord with schistosome eggs, although rare but do occurred, causing many neurologic complications. Saleem et al. (2005) in Egypt stated that spinal cord involvement is a rare manifestation of schistosomiasis. They described the MR imaging findings of eight spinal cord schistosomiasis in correlation with surgery and pathology. They concluded that multinodular intramedullary contrast enhancement of distal cord enabled correct presumptive preoperative MR imaging diagnosis of spinal schistosomiasis in three cases. Accurate diagnosis, by MR imaging appearance, allows early treatment and better prognosis of spinal cord schistosomiasis.

Angiostrongylus cantonensis, the rat lungworm, is a parasite that is endemic in Southeast Asia and Pacific caused an aseptic meningitis. Symptoms include severe headache, stiff neck, paresthesias, and uncommonly facial nerve palsy (Podwall et al, 2004). The diagnosis of cerebral angiostrongyliasis is generally based upon clinical presentation, CSF eosinophilia, and an epidemiologic history of known or possible exposure to infective $A$. cantonensis larvae. CSF protein concentration is usually elevated, but glucose concentration is normal or only minimally reduced. Peripheral blood and CSF eosinophilia frequently occur. Tsai et al. (2014) in Southeast Asia and the Pacific Islands stated that $A$. cantonensis is the main causative agent of human eosinophilic meningitis in. A previous study demonstrated that the 143-3 $\beta$ protein was a neuropathological marker in monitoring neuronal damage in meningitis. Steroids were commonly used in patients with A. cantonensis eosinophilic meningitis. They hypothesized that the beneficial effect of steroids on eosinophilic meningitis was partially mediated by the down-regulation of $14-3-3 \beta$ protein expression in the cerebrospinal fluid (CSF). Experimentally, they determined the dynamic changes of $14-3-3 \beta$ protein in mice with eosinophilic meningitis. The 14-3-3 $\beta$ protein in serum and CSF was increased in week $2 \& 3$ after infections. Dexamethasone significantly decreased the 
amounts of CSF 14-3-3 $\beta$ protein. By developing an in-house ELISA to measure 14-3$3 \beta$ protein, it was found that the amounts of $14-3-3 \beta$ protein in the CSF and serum increased over a three-week period after infection, with a remarkable reduction of 14-3-3 $\beta$ protein in the CSF after 2 weeks of dexamethasone treatment.

Abo-Madyan et al. (2005) in Al-Fayoum, Egypt in a survey carried out during Summer and Autumn, for snails of medical importance, nine species were recovered. These were Biomphalaria alexandrina, B. glabrata, B. pfeifferi, Bulinus truncatus, B. forskalii, Lymnaea natalensis, Bellamya unicolor, Physa acuta and Hydrobia musaensis. Examination revealed that B. alexandrina, $B$. glabrata and L. natalensis harbored immature stages of concerned trematode parasites. P. acuta harbored timmature stage of nematode parasite Parastrongylus cantonensis. Ibrahim (2007) at Al-Salam irrigation Canal and Al-Abtal village (north Sinai) reported six snails species were found infected with $A$. cantonensis larvae. These species were L. carinatus, C. bulimoides, C. cyclostomoides, B. alexandrina, L. natalensis and $M$. tuberculta, with prevalence ranged from 0.63 to $2.24 \%$, the peak in L. carinatus. He concluded that $A$. cantonensis larvae were found in a wide range of freshwater snails with $M$. tuberculata as a new intermediate host for the first times this zoonotic parasite.

Cestodes involve CNS, presented with varied clinical manifestation, at times causing diagnostic dilemmas.

As to echinococcosis Mazyad et al. (1998) in Egypt reported first time spinal cord hydatid cysts in two preparatory school pupils presented with sever back pain, bilateral neurologic deficient in both lower limbs including motor and sensory affection in scattered pattern as well as knees reflux. They were diagnosed hydatidosis by surgical removal of the cysts and confirmed by histological and parasitological examinations. They concluded that parasitic infection in the spinal cord is rare but it should be in mind with disseminating parasite(s). But, radical surgical excision was not always recommended. Biopsied materials for histopathological studies should be done first before any surgery. Ozdemir et al. (2004) in Turkey stated that bone involvement in hydatid disease was reported as 0.5 to $4 \%$. Spinal involvement is found in $50 \%$ of these cases, with mortality over $50 \%$. Paraplegia is the most serious complication of the disease, caused by compression of the spinal cord by the cysts. Aggressive surgery combined with antihelminthic therapy was recommended to eradicate the disease and prevent recurrence. They concluded that the primary spinal echinococcosis must be considered in the preoperative differential diagnosis of the atypical presentation of vertebral lesions, especially in patients with risk factors. Early diagnosis and preferably anterior radical surgery combined with antihelminthic therapy of sufficient duration are mandatory to at least halt the progression of symptoms, but these measures could not provide a lasting solution for these patients were described. Rumana et al. (2006) in India mentioned that in developing countries hydatidosis is both a medical and economic problem related to environmental hygiene and healthy veterinary practice. Multiple intracranial and spinal hydatidosis is rare. A series of 29 histologically confirmed cases of hydatidosis of neuraxis (21 intracranial and 8 spinal) from South India are presented. Among 21 cases of intracranial hydatidosis, 12 cases were in pediatric age, while only 1 spinal lesion was noted in a 5-year-old child. The clinical presentation of intracranial lesions was predominantly that of raised intracranial pressure and visual symptoms, while spinal hydatidosis manifested with severe back pain, weakness and sphincter disturbances. The cranial cysts were usually single and uniloculated (12 cases), multiple in 7 and single but multiloculated in 2 . In spinal hydatidosis, the cysts are usually multiple and extradural, rare ones being intramedullary and intradural. Based on the clinical features and 
imaging, the differential diagnosis for intracranial lesions were cystic tumors and arachnoid cyst while metastasis and tuberculosis were considered in cases of spinal hydatidosis because of vertebral bony involvement. The majority of the cysts could be surgically resected totally and some were aspirated under control suction and resected. None of the cases had anaphylactic reaction, with no significant post-operative morbidity and no mortality. One intracranial and 2 spinal lesions caused by fertile cysts recurred to undergo repeated surgery. Güneçs et al. (2009) in Turkey presented an unusual case of pathologically confirmed multiple distinct spinal intradural extramedullar spinal hydatid cyst after 1 year of lung cyst hydatid operation. A14-year-old boy admitted to clinic with pain in the back, both of leg and disability in walking. The patient presented with back pain, asymmetrical paraparesis, right more than left and weakness. Multiple distinct spinal intradural extramedullary cystic lesion was identified with magnetic resonance imaging and was hydatid cyst by histopathologic confirmation after the surgical removal. They reported that spinal hydatid disease is uncommon. Among them, multiple distinct spinal intradural extramedullar location is extremely rare. But total removed cysts without rupture should be the surgical goal in all cases, best treatment remains an active nationwide prevention of the disease.

Sasani and Ozer (2009) in Turkey mentioned that bone hydatid cysts occur in $1 \%$ to $2.5 \%$ of all patients with hydatid cyst disease, whereas $50 \%$ of bone hydatidosis cases are spinal. Diagnosis is difficult and patients usually present with neural compression symptoms. Surgery and antihelmintic medicine administration are considered as the treatments of choice. They reported a 35year-old male patient, who underwent surgical and antihelmintic medical treatment 2 years previously, had a leaking cyst without neurologic symptoms. The patient underwent excision of multiple parasacral cysts from a posterior approach. Medical antihel- mintic treatment was used after surgery. They concluded that the recurrence period of spinal hydatid disease may be silent without any neurologic deficits or pain; the only clinical manifestation may be leakage from a cyst. Curative therapies remain unlikely, but periodic follow-up MR images are advisable for early diagnosis of recurrence in order to obtain effective treatment.

Limaiem et al. (2010) in Tunisia analyzed the epidemiologic-characters, the clinical symptoms, radiological aspects, treatment and outcome of central nervous system hydatidosis and compared the results with those reported in literature. They were 20 male and 19 female patients (sex-ratio $\mathrm{M} / \mathrm{F}=1.05$ ) between 2 and 68 years of age (mean $=26.5$ years). Thirteen were children (33.3\%) with a mean age of 6.8 years and 26 were adults $(66.7 \%)$ with a mean age of 36.3 years. The location of hydatid cysts was intracranial in 27 cases $(69.2 \%)$ and spinal in 12 cases $(30.8 \%)$. Headache and motor deficits were predominant symptoms in patients with intracranial hydatidosis where-as back pain and spinal cord compression syndrome were the most frequent clinical presentations in patients with spinal hydatidosis. All patients underwent surgical resection of cyst. Pathologic findings were consistent with hydatid cyst in all cases. During follow-up period between 12 months and 5 years, 12 patients had recurrence $(30.7 \%)$. A patient with intracranial hydatid cyst died postoperatively due to anaphylactic shock. They concluded that despite all the advances in imaging techniques and therapeutic methods, central nervous system hydatidosis remains difficult to cure and patient outcomes are not satisfactory especially in case of spinal involvement due to the high incidence of recurrence.

As Taenia cysticercosis: Bouree et al. (2006) in France stated that cysticercosis caused by infection with the larva of Taenia solium, common the worldwide, is located in the muscles, eyes and the CNS, but mostly in the brain. Spinal cord infection was rare. 
They report a case of a young girl, living in Paris who had traveled in Latin America, and complained of back pains and troublesome walking. MRI showed a cyst in spinal cord, but other examinations were normal. Diagnosis was confirmed by a pathologist. It was a pure intramedullary cysticercosis, check-up to find other locations were negative. Only approximately 130 cases are reported in the literature, with motor and sensory disorders. The diagnosis was based on MRI and pathological examination. Antiparasitic medical treatment was useful when combined with surgery.

Khalifa et al. (2012) in Egypt reported that meurocysticercosis is a serious zoonotic diseas, encountered worldwide, caused by the larval stage of Taenia solium. Due to the difficulties facing scientists to study the biological, histological and immunological effects of these larvae on the human brain, other cestodes with more or less similar larvae (Taenia crassiceps) were used. In brain infected mice, Th1 predominant cytokines were significantly detected.

Luo et al. (2013) in China analyzed the epidemiological characteristics, the clinical symptoms, radiological aspects, treatments, and outcomes of primary CNShydatidosis and compared with those observed for secondary intracranial hydatidosis. They retrospectively reviewed 21 cases of primary CNS hydatid cysts operated on at the First Affiliated Hospital of Xinjiang Medical University between 1996 and 2010. They concluded that despite imaging and therapeutic advances, CNS hydatidosis remainsed difficult to treat, and severe complications and the high incidence of recurrence result in unsatisfactory outcomes.

Ahmed and Paul (2014) reported that neurocysticercosis usually presents with seizures, headaches, progressively worsening focal neurologic symptoms, visual disturbances, loss of bladder control, etc. The MRI scans can accurately diagnose spinal or cerebral lesions and is also helpful in monitoring progress while on treatment. Albend- azole was drug of choice along with steroids for management of neurocysticercosis.

As to toxoplasmosis, Morsy et al. (1978) in Jordan reported positive Toxoplasmin skin tests in children in a Royal Institute for Mentally Retarded Children.

Wishahy et al. (1975) in Egypt reported toxoplasmosis in children with some neurological manifestations and Rifaat et al. (1975) reported infantile toxoplasmosis and some neurological disorders. Mabrouk and Dahawi (1991) carried out study on 42 patients with meningoence-phalitis who had negative C.S.F. cultures for common pathogenic bacteria. Percentage of sero-positive Toxoplas$m a$ antibodies (IgG) by IIFA was $10 / 42$ (26\%). The clinical presentation \& C.S.F, changes with high antibody titers were encountered. The results may incriminate toxoplasmosis as an etiologic agent for meningo-encephalitis.

Prandota (2009) in Poland stated that approximately 2 billion people are chronically infected with $T$. gondii with largely unknown consequences. Various endogen-ous and exogenous triggering factors may markedly affect latent CNS T. gondii infection/ inflammation intensity, and cause reactivation of cerebral toxoplasmosis (CT). Irregularities in pro- and anti-inflammatory processes may markedly disturb the host and/or $T$. gondii defense mechanisms important for immune control of the parasite thereby manifesting as a wide range of neurologic symptoms and signs observed in some patients with migraine, epilepsy, celiac disease, Henoch-Schönlein purpura, and other brain disorders. This is consistent with reactivation of CT in mice after treatment with dexamethasone associated with depression of type $\mathrm{T}(\mathrm{H}) 1$ immune response, and development of CT after administration of etanercept or other bioproducts. The various types of headaches, epilepsy, aseptic meningitis, systemic adverse reactions to drugs or other substances represent the Jarisch-Herxheimer reaction due to the apoptosis of $T$. gondii tachyzoites. Development of some brain tu- 
mors, as ependymoma and glioma may be associated with a chronic course of CT.

Anwar et al. (2013) in Egypt reported that cerebral parasitic cysts constitute a major problem for livestock with coenurosis and toxoplasmosis the predominant. They concluded that coenurosis and toxoplasmosis played a significant role in sheep management.

Koshy and Cabral (2014) in USA stated that brain-Toxoplasma interaction is critical to the symptomatic disease produced by Toxoplasma, but with little understanding of the cellular or molecular interaction between cells of the central nervous system (CNS) and the parasite. In the mouse model of CNS toxoplasmosis it has been known for over 30 years that neurons are the cells in which the parasite persists, but little information is available about which part of the neuron is generally infected (soma, dendrite, axon) and if this cellular relationship changes between strains. In part, this lack was secondary to the difficulty of imaging and visualizing whole infected neurons from an animal. Such images would typically require serial sectioning and stitching of tissue imaged by EM or confocal microscopy after immunostaining. By combining several techniques, the method described here enables the use of thick sections $(160 \mu \mathrm{m})$ to identify and image whole cells that contain cysts, allowing three-dimensional visualization and analysis of individual, chronically infected neurons without the need for immunostaining, electron microscopy, or serial sectioning and stitching.

Generally, Abdel Razek et al. (2011) in Egypt reviewed the characteristic imaging appea-rances of parasitic diseases of CNS of cysticercosis, toxoplasmosis, cystic echinococcosis, schistosomiasis, amebiasis, malariasis, sparganosis, paragonimiasis, and American and African trypanosomiases. Routine precontrast and postcontrast MR imaging helps in localization, characterization, delineation of extension, and follow-up of the parasitic lesions. Moreover, recently devel- oped tools, such as diffusion, perfusion, and MR spectroscopy, help to differentiate parasitic diseases of the central nervous system from simulating lesions. Combining imaging findings with geographic prevalence, clinical history, and serologic tests is required for diagnosis of parasitic diseases of CNS. Yassin et al. (2010) in Doha reported a patient with skin lesions, respiratory distress, aseptic meningitis and bacterial and fungal sepsis, but fatal strongyloidiasis was established through endotracheal tube secretions. PradoPrado et al. (2011) in Spain developed a multi-target QSAR (mt-QSAR) classifier using the MARCH-INSIDE technique to calculate structural parameters of drug and target plus one Artificial Neuronal Network (ANN) to seek the model. The best ANN model found is a Multi-Layer Perceptron (MLP) with profile MLP 32:32-15-1:1. This MLP classifies correctly 623/678 DTPs (Sensitivity $=91.89 \%$ ) and 2995/3234 nDTPs (Specificity=92.61\%), corresponding to the training Accuracy $=92.48 \%$. The validation of model was carried out by means of external predicting series. The model classifies correctly 313/338 DTPs (Sensitivity = 92.60\%) and 1411/1534 nDTP (Specificity $=91.98 \%$ ) in validation series, corresponding to total Accuracy $=92.09 \%$ for validation series (Predictability). This model favorably compares with other LDA and ANN models developed in this work and Machine Learning classifiers published before to address the same problem in different aspects. These mt-QSARs offer also a good opportunity to construct drug-protein Complex Networks (CNs) that can be used to explore large and complex drug-protein receptors databases. They illustrated two practical uses of this model with two different experiments. In experiment 1 , reported prediction, synthesis, characterization, and MAO-A and MAO-B pharmacological assay of 10 rasagiline derivatives promising for anti-Parkinson drug design. In experiment 2 , found sampling, parasite culture, SEC \& 1DE sample preparation, MALDI-TOF MS \& MS/MS 
analysis, MASCOT search, MM/MD 3D structure modeling, and QSAR prediction for different peptides of hemoglobin found in the proteome of the human parasite Fasciola hepatica; which was promising for the antiparasite drug targets discovery. Othman et al. (2014) in Egypt reported that the helminthes infections of CNS occur worldwide with high prevalence in tropical and subtropical countries. They concluded that the helminthic CNS infections of global impact, such as schistosomiasis, neurotoxocariasis, strongyloidiosis, neurotrichinosis, neurocysticercosis, and echinococcosis.

Libbey et al. (2014) in USA stated that multiple sclerosis (MS) was an inflammatory demyelinating autoimmune disease of the CNS. Although etiology of MS is unknown, genetic and environmental factors play a role. Infectious pathogens are the likely environmental factors involved in the development of MS. Pathogens associated with the development or exacerbation of MS include bacteria, as Mycoplasma pneumoniae and Chlamydia pneumoniae, Staphylococcus aureus-produced enterotoxins that function as superantigens, viruses of the herpes virus (Epstein-Barr virus and human herpesvirus 6) and human endogenous retrovirus (HERV) families and the protozoa Acanthamoeba castellanii. They added that in contrast, certain parasites infection as Schistosoma mansoni, Fasciola hepatica, Hymenolepis nana, Trichuris trichiura, Ascaris lumbricoides, Strongyloides stercolaris, Enterobius vermicularis protected against the development or exacerbation of MS. Evidence supporting the ability of parasitic infections to protect against disease will be discussed along with a brief summary of a recent Phase I clinical trial testing the ability of Trichuris suis ova treatment to improve the clinical course of MS. A complex interaction between the CNS (including the blood-brain barrier), multiple infections with various infectious agents (occurring in the periphery or within the CNS), and the im- mune response to those various infections may have to be deciphered before the etiology of MS can be fully understood.

Neoplasms of Leptomeninges: Hematologic malignancies have a particular propensity to seed the CNS, especially large cell lymphomas and acute leukemias. Solid tumors frequently causing carcinomatous meningitis include breast cancer, lung cancer, melanoma, gastrointestinal malignancies, and cancers of unknown primary origin. Meningeal signs caused by tumor invasion of the leptomeninges and secondary inflammation are common. Headache, nausea, and vomiting may be presenting symptoms of increased intracranial pressure. Diagnosis of neoplastic meningitis is the cytologic identification of malignant cells within CSF, which profile may include an elevated protein concentration and a lymphocytic pleocytosis; a very high protein suggesting a CSF block. CSF eosinophilia can be seen in Hodgkin lymphoma.

Shinohara et al. (2016) in Japan reported a 66-year-old hospitalized man due to right leg pain. Computed tomography (CT) revealed multiple osteolytic changes. His serum prostate-specific antigen (PSA) level was increased to $77.83 \mathrm{ng} / \mathrm{ml}$ at the hospitalization time. A prostate biopsy was performed, and histological examination results indicated poorly differentiated adenocarcinoma. Under diagnosis of multiple bone metastasis of prostate cancer, androgen deprivation therapy was started. One month later, the patient was confused and lost appetite. Brain CT image demonstrated brain metastasis, and magnetic resonance image showed hydrocephalus. Although the patient underwent ventricular drainage because of a depressed level of consciousness, he died of primary disease complicated by pneumonia 3 months after the first visit. Perioperative cerebrospinal fluid cytological examination revealed adenocarcinoma cells.

Drug-Induced meningitis: The drug is an unusual adverse reaction that is usually a 
diagnosis of exclusion (Jolles et al, 2000). A number of drugs can induce symptoms and signs of aseptic meningitis included non-steroidal anti-inflammatory drugs (NSAIDs), certain antibiotics e.g., trimethoprim-sulfamethoxazole (Moris and Garcia-Monco, 1999) intravenous immune globulin, rofecoxib, cetuximab, and the OKT3 antibodies (Hoppmann et al, 1991). Two mechanisms were proposed for drug-induced meningitis: a delayed hyper-sensitivity type reaction and direct meningeal irritation (Lafferty al, 1997). The CSF profile typically has a neutrophilic pleocytosis. Symptoms often resolve a few days after drug discontinuation. There were also multiple reports of drug-induced meningitis in patients with autoimmune disease. Many reports implicate use of NSAIDs. It is unclear whether these patients are inherently at increased risk or whether the incidence is greater as a result of the prevalent usage of nonsteroidal anti-inflammatory drugs (Rodriguez et al, 2006). Koffman et al. (2016) in USA reported two cases, one was a 32 year-old woman admitted with nausea, vomiting and cranial nerve palsies. Serology was significant for a diagnosis of probable SLE. MRI was performed and showed bilateral symmetric diffuse T2/FLAIR hyperintensities throughout the white matter and cerebral angiography was unremarkable. The patient developed recalcitrant cerebral edema with intracranial hypertension despite immunosuppressive therapies and subsequently expired. Post mortem evaluation showed a white matter inflammatory process, but no vascular changes consistent with CNS vasculitis. Case two was a 29 year-old woman with known SLE that presented with a loss of consciousness. Imaging included a CT that showed diffuse cerebral edema with white matter involvement and a normal cerebral angiogram. Again, despite maximal medical management the patient herniated resulting in death by neurologic criteria. They concluded that the two cases represent a syndrome of white matter changes and diffuse cerebral edema associated with SLE that has yet to be reported in the literature. It is unclear if this process has a similar pathology to SLE related IIH. Because this syndrome causes a fulminant cerebral edema, further research is needed to better understand the underlying pathology and identify potential treatment options.

Approach to the patient: Clinical presentation of aseptic meningitis is generally nonspecific, with fever, headache, nausea and vomiting, occasionally accompanied by photophobia and a stiff neck. Physical examination typically reveals signs of nuchal rigidity. Approach to aseptic meningitis patients is complicated by diverse range of etiologic agents and limited available diagnostic tools.

Historical clues: Clinicians should bear in mind the following points: Obtain a comprehensive travel and exposure history, including exposure to rodents (LCM), ticks (Lyme), and tuberculosis, sexual activity (HSV-2, HIV, syphilis), and contact with other individuals with similar symptoms or viral exanthems (enteroviruses). Carefully consider potential nonviral etiologies. $\mathrm{Pa}$ tients should be specifically questioned about preceding use of drugs associated with meningitis as NSAIDs, intravenous immune globulin, trimethoprim-sulfamethoxazole.

Clues on physical examination: Physical examination may reveal findings suggestive of a specific agent: A diffuse maculopapular exanthem in a mildly ill patient may be consistent with enteroviral infection, primary HIV, or syphilis. The clinician should also be aware that a maculopapular rash cans occasionally in meningococcal infection and also Rocky Mountain spotted fever. Parotitis suggests mumps meningitis in an unvaccinated patient. Severe vesicular and ulcerative genital lesions suggested a primary episode of HSV-2 infection. Oropharyngeal thrush and cervical lymphadenopathy is consistent with primary HIV infection. Asymmetric flaccid paralysis strongly suggests the possibility of West Nile virus meningitis (El-Bahnasawy et al, 2013a).

Based upon the history, physical examina- 
tion, and CSF findings, patients can be classified as having probable bacterial meningitis, probable viral meningitis, or indeterminant. (See "Cerebrospinal fluid: Physiology and utility of an examination in disease states"). For patients with suspected bacterial meningitis (e.g., positive Gram stain, WBC count $>1000 /$ microL, glucose concentration $<40 \mathrm{mg} / \mathrm{dL}$ [2.2 mmol/L]), antibiotics should be initiated promptly. Patients with probable viral meningitis mainly with CSF findings of cell count $<500 / \mathrm{microL},>50 \%$ CSF lymphocytes, protein concentration less than 80 to $100 \mathrm{mg} / \mathrm{dL}$, normal glucose concentration, and negative Gram stain. Patients who are elderly, immunocompromised, or have received antibiotics prior to presentation should be given antibiotics even if viral meningitis is the suspected diagnosis. Otherwise, clinician can consider observing the patient without antibiotic therapy. When it is not clear whether the patient has a viral or bacterial process, the treating physician can choose empiric antibiotics after obtaining blood and CSF cultures or observation with repeat lumbar puncture (LP) in 6 to 24 hours. The majority of clinicians opt for empiric antibiotics until culture results are available in 24 to 48 hours. If the patient is symptomatically improved and culture results are negative, then antibiotics can generally be stopped without a repeat LP. Repeat LP may be indicated in patients with persistent symptoms who do not have a clear diagnosis. Examination of multiple parameters with the use of a nomogram may be helpful in deciding which patients should be treated empirically. However, Infectious Diseases Society of America guidelines on bacterial meningitis suggested that these prediction rules should not be used to make clinical decisions in individual patients. These guidelines can be accessed through the Infectious Diseases Society of America's website (Lavery et al, 2007). For patients with suspected viral meningitis or indeterminate CSF results, CSF must be sent for virus detection assay or virus culture, as well as for bacterial culture. In patients with cutaneous clues as to the etiology (e.g., genital herpes or herpes zoster), PCR testing is preferred. Other tests include: serum and CSF VDRL, HIV antibody or RNA testing, Lyme serology, and acute/convalescent serologic test for specific viruses. (Tunkel et al, 2004).

Differential diagnosis should be broadened for the patient with lymphocytic predominance in the CSF and negative bacterial cultures if symptoms worsen or persist. Evaluation should include a repeat CSF analysis with removal of large volume of fluid ( 3 to 5 $\mathrm{mL}$ ) for fungal and mycobacterial cultures, and imaging of the CNS and sinuses with magnetic resonance imaging (MRI) or computed tomography (CT). Potential noninfectious etiologies should also be considered.

\section{Recommendations}

The patient with aseptic meningitis may be difficultly diagnosed because of the large variety of potential etiologic agents and the overlap between self-limited viral illnesses and potentially fatal bacterial infections. A careful history should include travel and exposure history, including exposure to rodents (LCMV), ticks (Lyme Borrelia, RMSF, ehrlichia), mosquitoes (West Nile virus, St. Louis encephalitis virus) and patients with tuberculosis, sexual activity (HSV-2, HIV, syphilis), travel (Coccidioides immitis, Angiostrongylus cantonensis) and contact with others with similar symptoms or viral exanthems (enteroviruses). Patient should also be questioned about medications and other comorbidities. Opening CSF pressure should be noted and CSF should be sent for cell count, glucose, protein and culture or specific antigen or nucleic acid tests for viruses, as well as culture for bacteria. Whether additional studies (e.g., culture for fungi and mycobacteria) should be performed will depend on the clinical presentation (see discussion above and individual topic cards).

Based upon the history, physical examination and CSF findings, patients can often be classified as having probable bacterial or viral meningitis, although overlap can be 
frequent, particularly if bacterial meningitis has been partially treated with previous antibiotics.

For patients with suspected bacterial meningitis, antibiotics must be initiated promptly. The approach to empiric therapy in the patient with viral meningitis will depend upon the clinical appearance of the patient and underlying host factors. Elderly patients, immunocompromised, or have received antibiotics prior to presentation may be considered for empiric therapy for 48 hours, even if viral meningitis is the suspected diagnosis. Otherwise, clinician can consider patient observation without antibiotic.

If HIV was a diagnostic consideration, then blood testing for HIV RNA and HIV antibody should be performed. If aseptic meningitis due to HSV was suspected (e.g., concomitant genital lesions), empiric therapy with acyclovir (10mg every 8 hours) can be administered.

When etiology was not clear whether the patient has a viral or bacterial process, we recommend empiric antibiotics after obtaining blood and CSF cultures or observation with repeat lumbar puncture in 6 to $24 \mathrm{hrs}$. If the patient was symptomatically improved and culture results were negative, then antibiotics can generally be stopped without a repeat LP. Repeated LPs may be indicated in patients with persistent symptoms who did not have a clear diagnosis.

\section{References}

Abdel Razek, AA, Watcharakorn, A, Castillo, M, 2011: Parasitic diseases of the central nervous system. Neuroimaging Clin. N. Am. 21, 4: 815-41.

Abo-Madyan, AA, Morsy, TA, Motawea, SM, El Garhy, MF, Massoud, AM, 2005: Spot light survey on fresh-water snails of medical importance in Al Fayoum Governorate, Egypt. J. Egypt. Soc. Parasitol. 35, 1:49-58.

Ahmed, S, Paul, SP, 2014: Intramedullary spinal neurocysticercosis treated successfully with medical therapy. J. Egypt. Soc. Parasitol. 44, 3: 661-4.

Anwar, S, Mahdy, E, El-Nesr, KA, El-Dakhly, KM, Shalaby, A, et al, 2013: Monitoring of parasitic cysts in the brains of a flock of sheep in
Egypt. Rev. Bras. Parasitol. Vet. 22, 3:323-30.

Aronin, SI, Peduzzi, P, Quagliarello, VJ, 1998: Community-acquired bacterial meningitis: risk stratification for adverse clinical outcome and effect of antibiotic timing. Ann. Int. Med. 129:862-8.

Biggs, HM, Behravesh, CB, Bradley, KK, Dahlgren, FS, Drexler, NA, et al, 2016: Diagnosis and management of tickborne rickettsial diseases: Rocky Mountain Spotted Fever and other spotted fever group Rickettsioses, Ehrlichioses, and Anaplasmosis-United States. MMWR Recomm Rep. 65, 2:1-44.

Bodman, A, Riordan, M, Chin, LS, 2016: Delayed presentation of a cervical spinal epidural abscess of dental origin after a fall in an elderly patient. Cureus. May 23;8(5):e621. doi: 10.7759/ cureus.621.

Bouree, P, Dumazedier, D, Bisaro, F, Resende, P, Comoy, J, et al, 2006: Spinal cord cysticercosis: a case report. J. Egypt. Soc. Parasitol. 36, 3:727-36.

Chan, TY, Parwani, AV, Levi, AW, Ali, SZ, 2003: Mollaret's meningitis: cytopathologic analysis of fourteen cases. Diagn. Cytopathol. 28: 227-32.

Connolly, KJ, Hammer, SM, 1990: The acute aseptic meningitis syndrome. Infect. Dis. Clin. North Am. 4:599-604.

Corwin, A, Habib, M, Olson, J, Scott, D, Ksiazek, T, et al, 1992: The prevalence of arboviral, rickettsial, and Hantaan-like viral antibody in schoolchildren in the Nile river delta of Egypt. Trans. R. Soc. Trop. Med. Hyg. 86, 6:677-9

de Gans, J, van de Beek, D, 2002: Dexamethasone in adults with bacterial meningitis. $\mathrm{N}$. Engl. J. Med. 347:1549-52.

Djukic, M, Schmidt-Samoa, C, Lange, P, Spreer, A, Neubieser, K, et al, 2012: Cerebrospinal fluid findings in adults with acute Lyme neuroborreliosis. J. Neurol. 259, 4:630-6.

Domingo, P, Mancebo, J, Blanch, L, et al, 1988: Fever in adult patients with acute bacterial meningitis. J Infect Dis. 158:496-9.

Drago, F, Merlo, G, Ciccarese, G, Agnoletti, AF, Cozzani, E, et al, 2016: Changes in neurosyphilis presentation: a survey on 286 patients. J. Eur. Acad. Dermatol. Venereol. Jun 15. doi: 10. 1111/jdv.13753.

Durand, ML, Calderwood, SB, Weber, DJ, et $a l$, 1993: Acute bacterial meningitis in adults. N. Engl. J. Med. 328:21-9.

El-Bahnasawy, MM, Sabah, AA, Saleh, HA, 
Morsy, TA, 2012: The tick-borne Crimean-Congohemorrhagic fever in Africa, Asia, Europe, and America: what about Egypt? J. Egypt. Soc. Parasitol. 42, 2:373-84.

El-Bahnasawy, MM, Khater, MK, Morsy, T A, 2013a: The mosquito borne West Nile virus infection: is it threating to Egypt or a neglected endemic disease? J. Egypt. Soc. Parasitol. 43, 1: 87-102.

El-Bahnasawy, MM, Fadil, EE, Morsy, TA, 2013b: Mosquito vectors of infectious diseases: are they neglected health disaster in Egypt? J. Egypt. Soc. Parasitol. 43, 2:373-86.

Eldridge, BF, Glaser, C, Pedrin, RE, Chiles, RE, 2009: The first reported case of California Encephalitis in more than 50 years. Emerg. Infect. Dis. 7, 3:451-2.

Elhelw, RA, El-Enbaawy, MI, Samir, A, 2014: Lyme borreliosis: A neglected zoonosis in Egypt. Acta Trop. 140:188-92.

El-Kholy, AA, El-Rachidi, NG, El-Enany, M, AbdulRahman, E, Mohamed, R, et al, 2015: Impact of serology and molecular methods on improving the microbiologic diagnosis of infective endocarditis in Egypt. Infection 43, 5:523-9. Fitzgerald, N, Cross, M, O'Shea, S, Fox, J, 2016: Diagnosing acute HIV infection at point of care: a retrospective analysis of the sensitivity and specificity of a fourth-generation point-ofcare test for detection of HIV core protein p24. Sex Transm. Infect. Jun 7. pii: sextrans-2015052491. doi: 10.1136/sextrans-2015-052491.

Glimåker, M, Brink, M, Naucler, P, Sjölin, J, 2016: Betamethasone and dexamethasone in adult community-acquired bacterial meningitis: A quality registry study from 1995 to 2014. Clin. Microbiol. Infect. Jul 9. pii: S1198-743X (16) 30222-1

Gorman, MJ, Poddar, S, Farzan, M, Diamond, MS, et al, 2016: The interferon-stimulated gene IFITM3 restricts WNV infection and pathogenesis. J. Virol. Jul 6. pii: JVI.00581-16. [

Gulia-Nuss, M, Nuss, AB, Meyer, JM, Sonenshine, DE, Roe, RM, et al, 2016: Genomic insights into the Ixodes scapularis tick vector of Lyme disease. Nat. Commun. Feb 9;7:10507. doi: 10.1038/ncomms 10507 .

Güneçs, M, Akdemir, H, Tuğcu, B, Günaldi, O, Gümüçs, E, et al, 2009: Multiple intradural spinal hydatid disease: a case report $\&$ review of literature. Spine (Phila Pa 1976). 34, 9:E346-50.

Hikita, N, Seto, T, Yamashita, K, Iritani, N, Aata, M, et al, 2015: Relationship between ase- ptic meningitis severity and cerebrospinal fluid cytokine levels. Osaka City Med. J. 61, 2: 63-71. Hoppmann, R, Peden JG, Ober, SK, 1991: Central nervous system side effects of nonsteroidal anti-inflammatory drugs: Aseptic meningitis, psychosis, and cognitive dysfunction. Arch. Int. Med. 151:1309-16.

Humaid, AH, Ashraf, AH, Masood, KA, Nuha, AH, Saleh, AD, et al, 2014: Prevalence and risk factors of Otitis Media with effusion in school children in Qassim Region of Saudi Arabia. Int. J. Hlth. Sci. 8, 4:325-34.

Ibrahim, MM, 2007: Prevalence and intensity of Angiostrongylus cantonensis in freshwater snails in relation to some ecological and biological factors. Parasite 14, 1:61-70.

Ihekwaba, UK, Kudesia, G, McKendrick, MW, 2008: Clinical features of viral meningitis in adults: significant differences in cerebrospinal fluid findings among herpes simplex virus, varicella zoster virus, and enterovirus infections. Clin. Infect. Dis. 47:783-92.

Jolles, S, Sewell, WA, Leighton, C, 2000: Drug-induced aseptic meningitis: diagnosis and management. Drug Saf. 22:215-22.

Kelley, CF, Barbour, JD, Hecht, FM, 2007: The Relation Between Symptoms, Viral Load, and Viral Load Set Point in Primary HIV Infection. J. Acquir. Immune Defic. Syndr. 45:445

Khalifa, RM, Teale, JM, Mohamadain, HS, 2012: Studies on some metacestodes immunohistochemical response in mice as a model for human cysticercosis: II-THI type immune response in experimental Braintaenia crassiceps infected mice. J. Egypt. Soc. Parasitol. 42, 1:18390.

Koffman, L, Prayson, R, Manno, EM, 2016: Malignant cerebral edema related to Systemic Lupus Erythematosus. J. Neurol. Sci. 364:180-2. Koshy, AA, Cabral, CM, 2014: 3-D imaging and analysis of neurons infected in vivo with Toxoplasma gondii. J. Vis. Exp. Dec 9;(94). doi: 10.3791/52237.

Krbková, L, Homola, L, Hlaváčová, A, Mikolášek, P, Bednářová, J, et al, 2016: Assessment of antibodies against surface and outer membrane proteins of Anaplasma phagocytophilum in Lyme borreliosis and tick-borne encephalitis pediatric patients. Epidemiol. Infect. May 16:18.

Kupila, L, Vuorinen, T, Vainionpaa, R, et al, 2006: Etiology of aseptic meningitis and ence phalitis in an adult population. Neurology 66:75- 
80.

Kusne, S, Taranto, S, Covington, S, Kaul, DR, Blumberg, EA, et al, 2016: Coccidioidomycosis transmission through organ transplantation: A report of the OPTN AD HOC Disease Transmission Advisory Am. J. Transplant. Jul 4. doi: 10. 1111/ajt.13950.

Lafferty, TE, DeHoratius, RJ, Smith, J, 1997: Aseptic meningitis as a side effect of intravenous immune gammaglobulin. J. Rheumatol. 24: 2491-8.

Lavery, LA, Armstrong, DG, Murdoch, DP, Peters, EJ, Lipsky, BA, 2007: Validation of the Infectious Diseases Society of America's diabetic foot infection classification system. Clin. Infect. Dis. 44, 4:562-5.

Leber, AL, Everhart, K, Balada, JM, Cullison, J, Daly, J, et al, 2016: Multicenter evaluation of BioFire FilmArray meningitis encephalitis panel for the detection of bacteria, viruses and yeast in cerebrospinal fluid specimens. J. Clin. Microbiol. Jun 22. pii: JCM. 00730-16.

Leeyaphan, C, Jiamton, S, Prasertworonun, N, Maneeprasopchoke, P, Omcharoen, V, 2014: Clinical and epidemiological characteristics of patients with syphilis: 5 year-case study from Thailand. J. Med. Assoc. Thai. 97, 9:963-8. Libbey, JE, Cusick, MF, Fujinami, RS, 2014: Role of pathogens in multiple sclerosis. Int. Rev. Immunol. 33, 4:266-83.

Libbey, JE, Cusick, MF, Fujinami, RS, 2014: Role of pathogens in multiple sclerosis. Int. Rev. Immunol. 33, 4:266-83.

Limaiem, F, Bellil, S, Bellil, K, Chelly, I, Mekni, A, et al, 2010: Primary hydatidosis of the central nervous system: a retrospective study of 39 Tunisian cases. Clin. Neurol. Neurosurg. 112, 1:23-8.

Luo, K, Luo, DH, Zhang, TR, Wen, H, 2013: Primary intracranial and spinal hydatidosis: a retrospective study of 21 cases. Path. Glob. Hlth. 107, 2:47-51.

Mabrouk, MA, Dahawi, HS, 1991: Toxoplas$m a$ antibodies in patients with meningoencephalitis. J. Egypt. Soc. Parasitol. 21, 2:547-51.

Mazyad, MA, Mostafa, MM, Morsy, TA, 1998: Spinal cord schistosomiasis and neurollogic complications. J. Egypt. Soc. Parasitol. 28, 3:655-8.

Mazyad, MA, Mostafa, MM, Morsy, TA, 1999: Spinal cord schistosomiasis and neurologic complications. J. Egypt. Soc. Parasitol. 29, 1:179-82.
Meyer, HMJ, Johnson, RT, Crawford, IP, et $a l$, 1960: Central nervous system syndromes of "viral" etiology. Am. J. Med. 29:334-42.

Moris, G, Garcia-Monco, JC, 1999: The challenge of drug-induced aseptic meningitis. Arch. Int. Med. 159:1185-92.

Morsy, TA, EI Dasouqi, ST, Michael, SA, 1978: Toxoplasmin skin tests in mentally retarded children in Jordan. J. Egypt. Pub. Hlth. Assoc. 53, 1/2:87-90.

Othman, AA, Bruschi, F, Ganna, AA, 2014: Helminth parasitic infections of the central nervous system: a diagnostic approach. J. Egypt. Soc. Parasitol. 44, 1:55-70.

Ozdemir, HM, Ogün, TC, Tasbas, B, 2004: A lasting solution is hard to achieve in primary hydatid disease of the spine: long-term results and an overview. Spine (Phila Pa 1976). 29, 8: 932-7.

Papini, M, 2102: Herpes genitalis without frontiers: from clinical aspects to viral identification. G. Ital. Dermatol. Venereol. 147, 5:475-81.

Parasuraman, TV, Frenia, K, Romero, J, 2001: Enteroviral meningitis. Cost of illness and considerations for the economic evaluation of potential therapies. Pharmacoeconomics 19:3-9

Perez-Velez, CM, Anderson, MS, Robinson, CC, et al, 2007: Outbreak of neurologic enterovirus type 71 diseases: a diagnostic challenge. Clin. Infect. Dis. 45:950-9.

Pilcher, CD, Tien, HC, Eron, JJr, et al, 2004: Brief but efficient: acute HIV infection and the sexual transmission of HIV. J. Infect. Dis. 189: 1785-92.

Podwall, D, Gupta, R, Furuya, E, et al, 2004: Angiostrongylus cantonensis meningitis present with facial nerve palsy. J. Neurol. 251:1280-4.

Prado-Prado, F, García-Mera, X, Abeijón, P, Alonso, N, Caamaño, O, et al, 2011: Using entropy of drug and protein graphs to predict FDA drug-target network: Theoretic-experimental study of MAO inhibitors and hemoglobin peptides from Fasciola hepatica. Eur. J. Med. Chem. 46, 4:1074-94.

Prandota, J, 2009: The importance of Toxoplasma gondii infection in diseases presenting with headaches. Headaches and aseptic meningitis may be manifestations of the Jarisch-Herx-heimer reaction. Int. J. Neurosci. 119, 12:2144-82. Ragab, A, Farahat, T, Al-Hendawy, G, Samaka, R, Ragab, S, et al, 2015: Nasal saline irrigation with or without systemic antibiotics in 
treatment of children with acute rhinosinusitis. Int. J. Pediatr. Otorhinolaryngol. 79, 12:2178-86. Rawal, G, Yadav, S, Wani, UR, Ambastha, A K, 2015: HSV Encephalitis with normal CSF A case report with review of literature. J. Clin. Diagn. Res. 9, 12:OD06-7.

Reisen, WK, Wheeler, SS, 2016: surveys for antibodies against mosquitoborne encephalitis viruses in California Birds, 1996-2013. Vector Borne Zoonotic Dis. 16, 4:264-82.

Rifaat, MA, Wishahy, AO, Morsy, TA, Sadek, MSM, Hussein, D, 1975: Toxoplasmosis and some neurological disorders in Egypt. J. Egypt. Pub. Hlth. Assoc. 50, 1:1-10.

Rodriguez, SC, Olguin, AM, Miralles, CP, Viladrich, PF, 2006: Characteristics of meningitis caused by Ibuprofen: report of 2 cases with recurrent episodes and review of literature. Medicine (Baltimore), USA.

Rousseau, MC, Saron, MF, Brouqui, P, Bourgeade, A, 1997: Lymphocytic choriomeningitis virus in southern France: four case reports and a review of the literature. Eur J. Epidemiol. 13: 817-22.

Rumana, M, Mahadevan, A, Nayil-Khurshid, M, Kovoor, JM, Yasha, TC, et al, 2006: Cestode parasitic infestation: intracranial and spinal hydatid disease, a clinicopathological study of 29 cases from South India. Clin. Neuropathol. 25, 2:98-104.

Saleem, S, Belal, AI, El-Ghandour, NM, 2005: Spinal cord schistosomiasis: MR imaging appearance with surgical and pathologic correlation. AJNR Am. J. Neuroradiol. 26, 7:1646-54.

Sasani, M, Ozer, AF, 2009: Spontaneous drainage of an asymptomatic recurrent hydatid cyst of sacrum. Spine (Phila Pa 1976). 34, 7:E269-71.

Schafer, IJ, Miller, R, Ströher, U, Knust, B, Nichol, ST, et al, 2015: Notes from the field: a cluster of lymphocytic choriomeningitis virus infections transmitted through organ transplantation-Iowa, 2013. MMWR Morb Mortal Wkly Rep. 2014 Mar 21;63(11):249.

Schlesinger, Y, Tebas, P, Gaudreault-Keener, M, et al, 1995: Herpes simplex virus type 2 meningitis in the absence of genital lesions: Improved recognition with use of the polymerase chain reaction. Clin. Infect. Dis. 20:842-9.

Schneider, MA, Pomidor, MA, 2016: Cerebral mycotic aneurysm and infective endocarditis: A case study. J. Neurosci. Nurs. 48, 2:100-4.

Shalabi, M, Whitley, R, 2006: Recurrent benign lymphocytic meningitis. Clin. Infect. Dis.
43:1194-9.

Shinohara, M, Kiba, K, Yamada, A, Hatakeyama, K, Mita, Y, et al, 2016: A Case of difficult-to-diagnose carcinomatous meningitis caused by prostate cancer metastasis. Hinyokika Kiyo $62,5: 265-9$.

Sun, D, Shi, M, 2016: Neutrophil swarming toward Cryptococcus neoformans is mediated by comple-ment and leukotriene B4. Biochem. Biophys, Res, Commun. Jul 8. pii: S0006-291X (16) 31120-2. doi: 10.1016/j.bbrc. 2016.07.005.

Takeshima, S, Yoshimoto, T, Shiga, Y, Kanaya, Y, Neshige, S, et al, 2015: Clinical, epidemiological and etiological studies of adult aseptic meningitis: Report of 13 cases with mumps meningitis. Rinsho Shinkeigaku. 55, 9:630-6

Toom, ML, Dobak, TP, Broens, EM, Valtolina, C, et al, 2016: Interstitial pneumonia and pulmonary hypertension associated with suspected ehrlichiosis in a dog. Acta Vet. Scand. 58, 1:46-50.

Tsai, HC, Lee, BY, Yen, CM, Wann, SR, Lee, SS, et al, 2014: Dexamethasone downregulated the expression of CSF 14-3-3 $\beta$ protein in mice with eosinophilic meningitis caused by Angiostrongylus cantonensis infection. Acta Trop. 131:98-103.

Tunkel, AR, Hartman, BJ, Kaplan, SL, et al, 2004: Practice guidelines for management of bacterial meningitis. Clin. Infect. Dis. 39:1267-78.

Tyler, KL, 2009: Emerging viral infections of the central nervous system: Part 1. Arch. Neurol. 66:939-46.

Whitley, RJ, Kimberlin, DW, 2005: Herpes simplex encephalitis: children and adolescents. Semin Pediatr Infect Dis 2005; 16:17-22.

Wishahy, AO, Rifaat, MA, Morsy, TA, EI Naggar, BA, 1975: Toxoplasmosis in children with some neurological manifestations. J. Trop. Med. Hyg. 75, 12:255-6.

Woo, TM, 2016: Postexposure Management of Vaccine-Preventable Diseases. J. Pediatr. Hlth. Care 30, 2:173-84,

Yassin, MA, El Omri, H, Al-Hijji, I, Taha, R, Hassan, R, et al, 2010: Fatal Strongyloides stercoralis hyper-infection in a patient with multiple myeloma. Braz. J. Infect Dis. 14, 5:536-9.

Xu, Y, Wan, L, Ning, J, Guo, W, Ren, L, 2016: Paroxysmal sympathetic hyperactivity in a child with Tuberculous meningitis a case study and review of related literature. West Indian Med. J. Apr 18. pii: wimj.055. 